\title{
Mobitz II AV block within the His bundle, with progression to complete heart block
}

\author{
Luis M. Amuchástegui, Eduardo Moreyra, and Luis E. Alday \\ From the Departamento de Hemodinamia, Hospital San Roque Obispo Salguero 50, Córdoba, Argentina
}

$A$ case of a 48-year-old woman with frequent syncopal episodes is reported. The electrocardiogram showed high degree $A V$ block with narrow $Q R S$ complexes. The His bundle electrogram displayed a split His deflection indicating impairment of conduction within the His bundle of the Mobitz II type. The AH interval was prolonged and Wenckebach phenomenon occurred at the same atrial pacing rate before and after atropine administration. During spontaneous or induced high grade AV block an escape rhythm originating in the distal His bundle was observed.

A second study performed one year later showed progression to complete AV block. Both His potentials were present, one following the atrial and the other preceding the ventricular deflection. The $H^{\prime} V$ interval was prolonged and a further lengthening was seen after ajmaline. All these findings indicated proximal, mid, and distal disease of the His trunk.

Different degrees of atrioventricular conduction disturbances may occur within the His bundle (Narula, Scherlag, and Samet, 1969; Narula and Samet, 1970). High grade second degree AV block and complete AV block caused by lesions in the His bundle may be suspected in the electrocardiogram if the QRS complexes are narrow (Narula and Samet, 1970). These diagnoses may be confirmed if split His deflections are recorded in the His bundle electrogram (Schuilenburg and Durrer, 1972; Gupta, Lichstein, and Chadda, 1972). The purpose of this communication is to report a case of high degree Mobitz II AV block which progressed to complete heart block within one year. Initially, the His bundle electrogram showed split His potentials and when complete heart block developed the subsidiary pacemaker was located in the distal His bundle.

\section{Case report}

The patient was a 48-year-old woman with frequent syncopal episodes. There was no history of chest pain or high blood pressure. Serological investigations for Chagas' disease were negative. The electrocardiogram showed Mobitz II type second degree AV block, with a PR interval of $0.26 \mathrm{~s}$ in the conducted beats and QRS complexes of $0.10 \mathrm{~s}$ duration displaying a right bundle-branch con- duction disturbance pattern. Following two or more blocked sinus $\mathbf{P}$ waves, escape junctional beats occurred with a slightly different QRS morphology and similar duration. Blocked supraventricular extrasystoles were also present.

A His bundle electrogram was obtained with the standard technique (Scherlag et al., 1969). Another bipolar electrode catheter was placed in the high right atrium to record an atrial electrogram. The same catheter was used for atrial pacing. All tracings were recorded at a speed of $100 \mathrm{~mm} / \mathrm{s}$. A direct writing eight-channel Elema recorder was employed.

The initial tracing showed 1:1 AV conduction. Two His bundle spikes were recorded in the AV interval. The $\mathrm{AH}$ interval measured $125 \mathrm{~ms}$, the $\mathrm{HH}^{\prime}$ interval $95 \mathrm{~ms}$, and the $\mathrm{H}^{\prime} \mathrm{V}$ interval $30 \mathrm{~ms}$. The QRS morphology in V1 showed an incomplete right bundle-branch block pattern. Fig. 1 is a continuous recording showing spontaneous changes in AV conduction. The first 5 beats are similar to those seen in the initial tracing and have an almost constant $\mathrm{HH}^{\prime}$ interval varying between 85 and 92 ms. The sixth atrial beat of the atrial electrogram was premature and occurs simultaneously with the fifth QRS complex initiating a period of three blocked A waves followed by $\mathrm{H}$ at the same previous interval. The AV conduction was then interrupted and an escape rhythm lasting for 6 beats was 

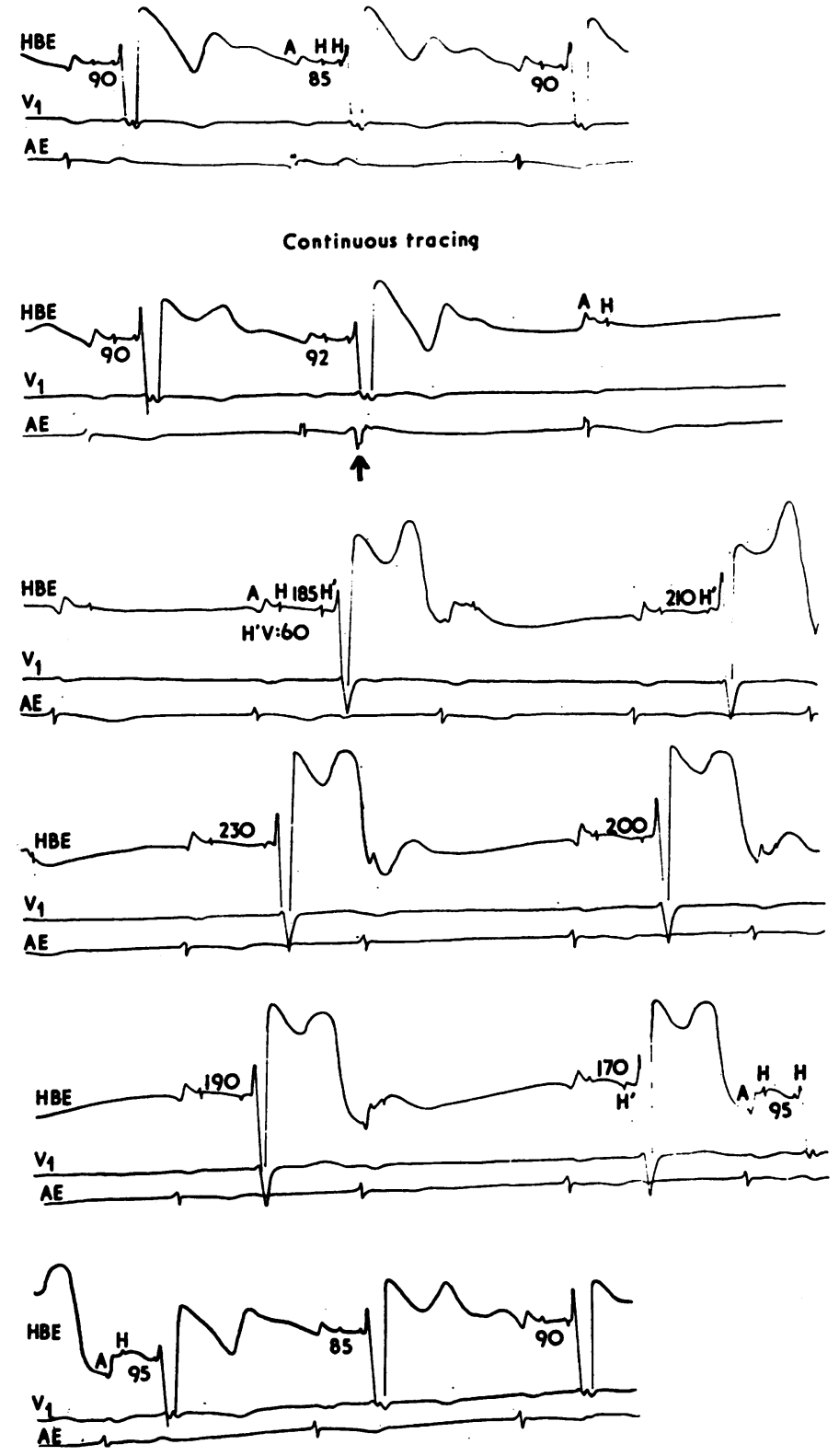

FIG. 1 Continuous tracing. From top to bottom, His bundle electrogram (HBE), lead V1, and atrial electrogram ( $A E$ ), are displayed. The numbers indicate the length of the $\mathrm{HH}^{\prime}$ intervals in ms. The sixth atrial complex (arrow) is premature and occurs simultaneously with the fifth $Q R S$ complex. For further explanation see text. 

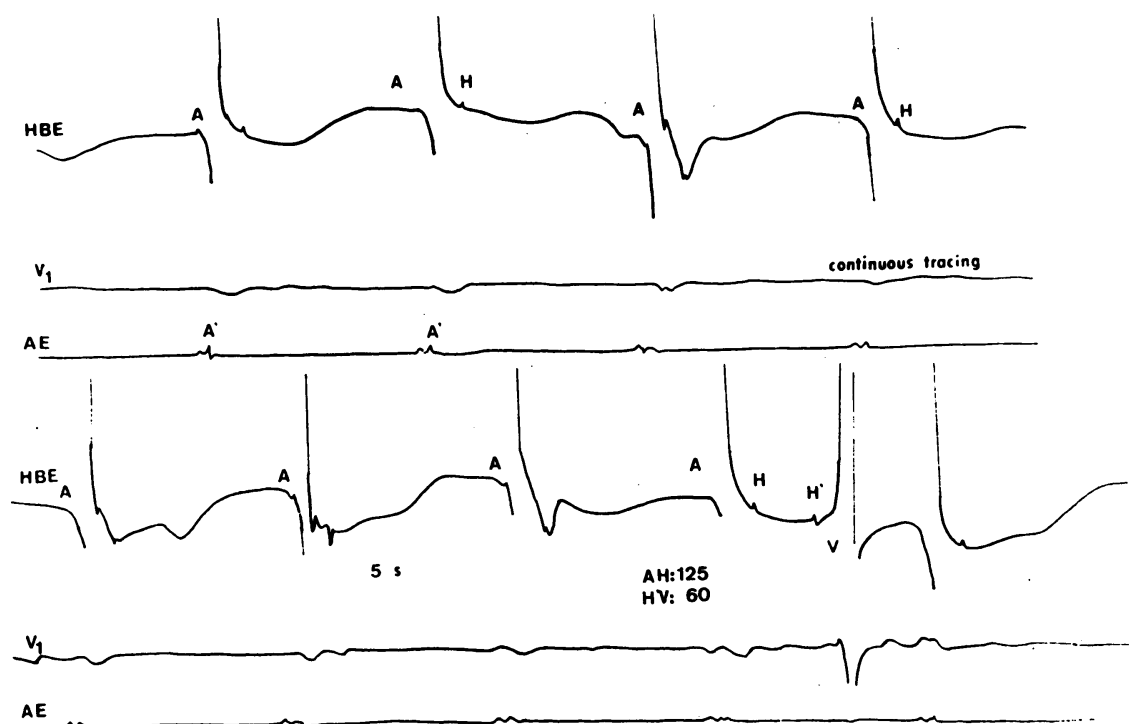

FIG. 2 Continuous tracing showing a long period of $A V$ block. Every $A$ wave is followed by an $H$ deflection at the same interval. Following the eighth $A$ wave an escape beat appears. Abbreviations as in previous figure.

observed. The escape beats during this period were preceded by an $\mathrm{H}^{\prime}$ deflection with an $\mathrm{H}^{\prime} \mathrm{V}$ interval of $60 \mathrm{~ms}$ which was much longer than that observed in conducted beats. The QRS configuration in V1 during this rhythm did not show the IRBBB pattern. Every second atrial complex was followed by an $\mathrm{H}^{\prime}$ spike, but the changing $\mathrm{HH}^{\prime}$ interval indicated that there were two independent rhythms. One-to-one AV conduction resumed after the sixth escape beat. Fig. 2 shows a more severe depression of the $\mathrm{AV}$ conduction lasting $5 \mathrm{~s}$ also occurring spontaneously. Every A deflection was followed by $\mathrm{H}$ at the same interval and the escape beat had the same characteristics as those of the previous figure.

Atrial pacing at a rate of $100 / \mathrm{min}$ induced $2: 1 \mathrm{AV}$ block. Every A deflection was followed by $\mathrm{H}$ when nonconducted. In the conducted beats the two $\mathrm{H}$ deflections appeared as in the basal tracing. The $\mathrm{AH}$ interval was prolonged to $180 \mathrm{~ms}$ in both blocked and conducted beats. The $H^{\prime} \mathrm{V}$ interval and the QRS morphology in V1 were unchanged. Also noted were the occurrence of higher degrees of $\mathrm{AV}$ block with escape beats similar to those already described. An increase in the atrial pacing rate to $120 /$ min induced Wenckebach phenomenon in the $\mathrm{AH}$ interval. Atropine administration also induced 2:1 intra-His AV block but did not change the basal $\mathrm{AH}(130 \mathrm{~ms}), \mathrm{HH}^{\prime}(95 \mathrm{~ms})$, or $\mathrm{H}^{\prime} \mathrm{V}(30 \mathrm{~ms})$ intervals. Atrial overdriving after atropine again elicited a Wenckebach phenomenon in the $\mathrm{AH}$ interval at an atrial pacing rate of $120 / \mathrm{min}$.

A permanent transvenous demand pacemaker was inserted and she did well for about a year when once again she started to notice dizziness; intermittent pacemaker failure was diagnosed. The pacemaker malfunction was the result of increased endocardial threshold. A new unit with epicardial electrodes was implanted. A His bundle electrogram was repeated at the time of replacement. The second study showed complete AV block with an atrial rate of 90 per minute. Every A wave was followed by $\mathrm{H}$ at an interval of $140 \mathrm{~ms}$. The ventricular rate was 43 per minute. All ventricular complexes were similar in morphology to those seen in the escape beats of the first study and were preceded by an $\mathrm{H}^{\prime}$ deflection with an $\mathrm{H}^{\prime} \mathrm{V}$ interval of $60 \mathrm{~ms}$ (Fig. 3). Ajmaline, $50 \mathrm{mg}$, was given intravenously inducing prolongation of the $\mathrm{H}^{\prime} \mathrm{V}$ interval to $75 \mathrm{~ms}$ (Fig. 3). The AH interval and the ventricular rate did not change.

\section{Comment}

The His bundle electrogram unmasked the site and mechanism of block in this patient. The presence of split His potentials separated by a $95 \mathrm{~ms}$ interval indicated a conduction disturbance within the His bundle. The first $\mathrm{H}$ deflection was a proximal $\mathrm{His}$ potential as supported by the prolongation of the AH interval during pacing. The origin of the $\mathrm{H}^{\prime}$ deflection in the conducted beats was probably 

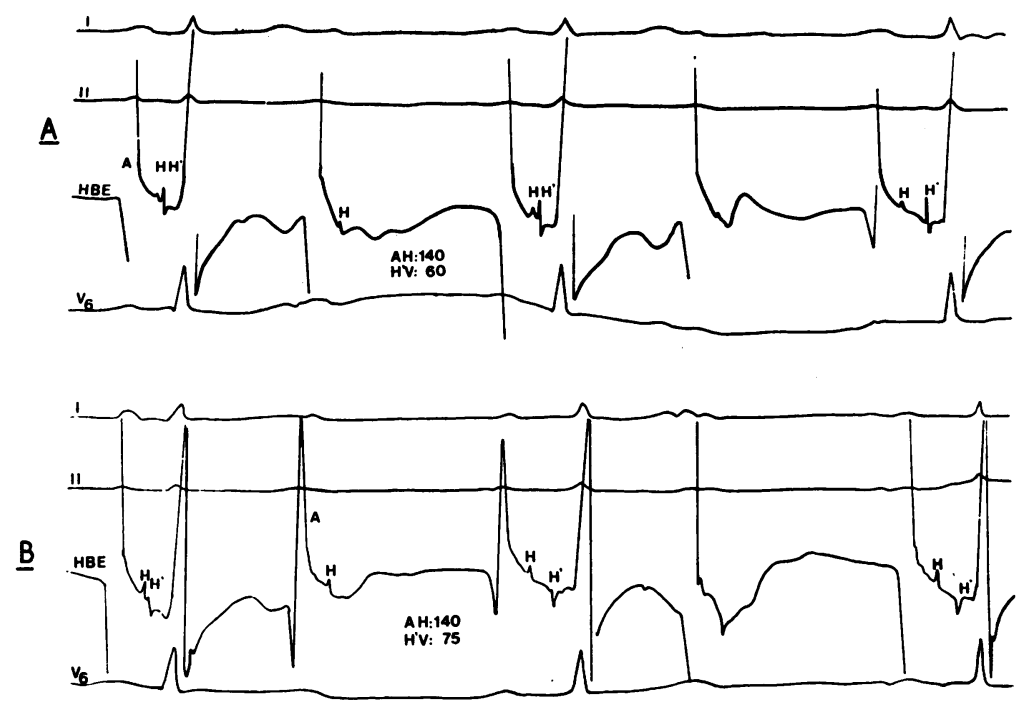

FIG. 3 (A) Basal tracing of the second study showing complete AV block. The ventricular complexes are preceded by $H^{\prime}$ deflections and every atrial complex is followed by $H$ at the same interval. (B) Tracing displaying the effect of $50 \mathrm{mg}$ ajmaline given intravenously. The $H^{\prime} V$ interval has been prolonged from 60 to $75 \mathrm{~ms}$. The AH interval remains unchanged. The His bundle electrogram (HBE) has been recorded simultaneously with leads I, II, and V6.

in the right bundle-branch since the $\mathrm{H}^{\prime} \mathrm{V}$ interval was only $30 \mathrm{~ms}$. The $\mathrm{HH}^{\prime}$ interval of all conducted beats remained constant indicating that the type of block present in this patient was Mobitz II within the His bundle.

During episodes of higher degrees of heart block, either occurring spontaneously or induced by atrial pacing, escape beats from the distal part of the His bundle appeared. These escapes were initiated by an $\mathrm{H}^{\prime}$ deflection with an $\mathrm{H}^{\prime} \mathrm{V}$ interval of $60 \mathrm{~ms}$. The lack of relation between $\mathrm{H}$ and $\mathrm{H}^{\prime}$ signals indicated the existence of independent rhythms. The longer $\mathrm{H}^{\prime} \mathrm{V}$ interval in the escape beats as opposed to the conducted beats suggested that the subsidiary pacemaker was located in the distal His bundle. It was also noticed that the QRS morphology showing an incomplete right bundle-branch block pattern in the conducted beats changed to a more normal configuration during the escape rhythm even though the QRS width did not change significantly. The apparent improvement of intraventricular conduction could be explained on the basis that the right bundle-branch disturbance was rate dependent (García and Rosenbaum, 1972).

Right atrial pacing and atropine administration induced higher degrees of $\mathrm{AV}$ block with the expected opposite effects on the AH interval. However, this interval remained longer than normal $(130 \mathrm{~ms})$ even after atropine. A prolonged $\mathrm{AH}$ interval could be either the result of a conduction delay in the AV node or in the proximal His bundle. Since atropine does not improve conduction through the His bundle as shown by Akhtar et al. (1974), it is most likely that the delay occurred in the infra-AV nodal origin of the His trunk. This was further supported by the fact that Wenckebach phenomenon in the AH interval occurred at the same atrial pacing rate both before and after atropine administration.

The follow-up study obtained after a year at the time of pacemaker replacement disclosed complete heart block within the His bundle. Every A deflection was followed by $\mathrm{H}$ and the ventricular deflection was preceded by $\mathrm{H}^{\prime}$. The $\mathrm{H}^{\prime} \mathrm{V}$ interval and the QRS configuration were similar to those seen in the first study during the escape rhythm. The lengthening of the $\mathrm{H}^{\prime} \mathrm{V}$ interval observed with ajmaline administration with no change in the atrial or ventricular rates supported the origin of $\mathrm{H}^{\prime}$ in the distal His bundle (Camerini et al., 1973).

This patient displayed several interesting features. When she was first studied there was Mobitz II AV block within the His bundle with narrow $Q R S$ complexes. During spontaneous or induced higher degrees of AV block the subsidiary pacemaker was located in the distal His bundle. At the time of the second study the block had progressed to third degree with the same subsidiary pacemaker. On both 
occasions the two potentials originated in the His bundle were recorded without any difficulty. It has recently been mentioned that in certain cases the recording of split His signals might be technically difficult (Schuilenburg and Durrer, 1975).

The prolonged $\mathrm{AH}$ interval with the occurrence of Wenckebach phenomenon at similar atrial pacing rates before and after atropine, the split His signal with progression to complete AV block, and the long $\mathrm{H}^{\prime} \mathrm{V}$ interval which lengthened further with ajmaline, indicated proximal, mid, and distal disease of the His trunk ('pan His disease').

\section{References}

Akhtar, M., Damato, A. N., Caracta, A. R., Batsford, W. P., Josephson, M. E., and Lau, S. H. (1974). Electrophysiologic effects of atropine on atrioventricular conduction studied by His bundle electrogram. American fournal of Cardiology, 33, 333.

Camerini, F., Baldi, N., Gori, P., and Martinoli, E. (1973). L'ajmalina nello studio prognostico dei blocchi bifasicolari. E'possible valutare il rischio di evoluzione verso il blocco totale. Giornale Italiano di Cardiologia, 3, 880.
Garcia, H., and Rosenbaum, M. B. (1972). El 'efecto fuelle' en los bloqueos intermitentes de rama. Revista Argentina de Cardiologia, 40, 75.

Gupta, P. K., Lichstein, E., and Chadda, K. D. (1972). Electrophysiological features of Mobitz type II AV block within the His bundle. British Heart fournal, 34, 1232.

Narula, O. S., and Samet, P. (1970). Wenckebach and Mobitz type II A-V block due to block within the His bundle branches. Circulation, 41, 947.

Narula, O. S., Scherlag, B. J., and Samet, P. (1969). His bundle blocks and His bundle rhythms. Diseases of the Chest, 56, 238.

Scherlag, B. J., Lau, S. H., Helfant, R. H., Berkowitz, W. D., Stein, E., and Damato, A. N. (1969). Catheter technique for recording His bundle activity in man. Circulation, 39, 13.

Schuilenburg, R. M., and Durrer, D. (1972). Conduction disturbances located within the His bundle. Circulation, 45, 612 .

Schuilenburg, R. M., and Durrer, D. (1975). Problems in the recognition of conduction disturbances in the His bundle. Circulation, 51, 68.

Requests for reprints to Dr. Luis M. Amuchástegui, Departamento de Hemodinamia, Hospital San Roque, Obispo Salguero 50, 5000 Córdoba, Argentina. 